\title{
Early diagnosis and differences in progression of
}

\section{fetal encephalocele: a case series}

\author{
Alston G.J. Ong, MBBS (Hons) ${ }^{1}$; Daniel L. Rolnik, MSc, MD, $\mathrm{PhD}^{1}$; Melody Menezes, \\ BSc (Hons), PhD, MHGSA²; Simon Meagher, BSc (Hons), FRCOG, FRANZCOG, COGU²
}

1. Department of Obstetrics and Gynaecology, Monash University, Melbourne, Victoria, Australia

2. Monash Ultrasound for Women, Melbourne, Victoria, Australia

\author{
Corresponding author: \\ Daniel L. Rolnik \\ Department of Obstetrics and Gynaecology \\ Monash University \\ 246 Clayton Road, Clayton 3168, Victoria, Australia \\ E-mail: daniel.rolnik@monash.edu \\ Phone: +61452105 585
}

Running Title: Early prenatal diagnosis of fetal encephalocele

This is the author manuscript accepted for publication and has undergone full peer review but has not been through the copyediting, typesetting, pagination and proofreading process, which may lead to differences between this version and the Version of Record. Please cite this article as doi: $10.1002 /$ jum.15217

This article is protected by copyright. All rights reserved. 


\section{Summary}

In this case series, we present three cases of very early prenatal diagnosis of encephaloceles that, despite similar appearances at diagnosis, had different disease progressions. Two of the cases were carried to term while one resulted in a termination of pregnancy. The diagnoses were made via ultrasound examination prior to cell-free DNA testing for chromosomal abnormalities screening at 10 weeks of gestation, thereby highlighting the importance of performing routine ultrasound examination prior to cell-free DNA testing antenatally. 


\section{Introduction}

Encephalocele is estimated to affect 0.8 to 5 per 10,000 live births, ${ }^{1}$ with the prognosis being dependent on the amount of herniated neural tissue and associated anomalies. ${ }^{2}$ The mortality rate is estimated to be around $30 \%,{ }^{3}$ while seizure disorders are present in approximately $20 \%$ of the surviving patients with congenital encephalocele. ${ }^{4}$ Up to $75 \%$ of encephaloceles are occipital in location, while others can be frontal or parietal. ${ }^{5}$ Prenatal diagnosis is usually made via ultrasound.

Prenatal ultrasonography for morphological assessment of the fetus is usually performed during early pregnancy between 11-14 weeks gestation and this allows for screening of a wide range of congenital anomalies, including central nervous system conditions such as neural tube defects (NTDs). ${ }^{5}$ Traditional two-dimensional ultrasound detects approximately $80 \%$ of encephaloceles, and these diagnoses are usually made in the second trimester. ${ }^{2}$ The use of three-dimensional (3D) ultrasound since 1992 has also led to earlier diagnosis of many congenital anomalies including encephaloceles. ${ }^{2}$ Furthermore, in the current era of cell-free DNA (cfDNA) analysis on maternal blood for common fetal chromosomal aneuploidies, ultrasound is often performed between nine and 11 weeks of gestation, prior to cfDNA testing. These ultrasounds aim to ensure accurate gestational age, and to rule out situations in which the test should not be performed, namely miscarriage and presence of a demised (“vanishing”) twin. ${ }^{6}$ Detection of major fetal abnormalities have been reported before 11 weeks of gestation and have the potential to alter screening and diagnostic pathways. ${ }^{7,8}$ Although poor prognostic factors for occipital encephaloceles have been identified, namely size of herniated brain tissue, presence of other complications such as ventriculomegaly, 
microcephaly or other congenital abnormalities, ${ }^{3}$ no literature on the antenatal evolution of the lesion is available, particularly when diagnosed in early pregnancy.

In this case series, we present three cases of encephaloceles detected in early pregnancy (before 11 weeks of gestational age) that had different progression of the disease throughout gestation, thereby shedding some light on the evolution of said condition and also highlighting the importance and significance of performing a pre-test ultrasound examination for patients who opt to have cfDNA testing as a primary screening test for fetal chromosomal abnormalities. Ethics approval was not needed as this is a case series, and informed consent was obtained from the patients for the use of de-identified ultrasound images.

This article is protected by copyright. All rights reserved. 


\section{Case 1}

A 37-year-old G2P1 underwent in-vitro fertilization (IVF) with a day five frozen single embryo transfer. Her past medical history included having had an emergency caesarean section in the previous pregnancy due to failure to progress in labor and a laparoscopic appendicectomy. Her first child was born with an occipital hemangioma and there were no other perinatal complications. She was otherwise healthy with no medical co-morbidities.

On her seventh week ultrasound examination, which was performed to asses embryonic viability, the embryo was found to be seven days behind in terms of size with no other appreciable abnormalities. A pre-cfDNA testing scan was performed on the eleventh week and the fetus was found again to be five days behind in terms of size (crown-rump length equivalent to 10 weeks and 6 days), based on IVF estimated date of delivery (EDD). A small sac-like structure arising from the posterior aspect of the fetal occipital bone was noted (Figure 1A), which was suspected to be an encephalocele. As a result, the patient did not proceed to have cfDNA testing. On follow-up ultrasound examination at 13 weeks of gestation, the defect increased in size (Figure 1B), measuring 7 x $6 \mathrm{~mm}$. After counselling, the patient opted to have diagnostic testing via amniocentesis, which was uneventfully performed at 16 weeks of gestation and demonstrated normal fetal chromosomal microarray. On the 22 weeks morphology ultrasound, the bony defect was not visualized as a result of the fetal occiput position. The lesion was then visualized again on all subsequent scans, and also seen on a magnetic resonance imaging (MRI) examination performed at 24 weeks of gestation (Figure 1C), which showed a midline occipital cephalocele measuring 14 x 14 x 5 $\mathrm{mm}$, and containing a $2 \mathrm{~mm}$ vascular structure at the skull vault defect in continuity with the 
straight sinus and no apparent herniation of brain tissue. She proceeded to have an elective caesarean section as it was difficult to rule out any possibility of brain tissue being involved in the occipital defect. The child was born in good condition with a birth weight of $3300 \mathrm{~g}$, Apgar scores of 9 and 9, at one and five minutes of life, respectively. Subsequent work-up by the Neurosurgery team had ruled out any involvement of brain tissue. The child is growing well and currently scheduled for routine follow-up with the Neurosurgical team without ongoing plans for active intervention. The postnatal aspect of the lesion can be seen in Figure $1 \mathrm{D}$.

\section{Case 2}

A 30-year-old primigravida without any significant past medical history was referred by her General Practitioner (GP) for cfDNA testing at 10 weeks and 6 days of gestation. The precfDNA test ultrasound showed an appropriate embryo size and a small 2 x 3 mm cystic lesion in the fetal occiput region (Figure 2A). The fetal midbrain was also found to be displaced posteriorly, and the differential diagnoses made at this stage included meningocele or a meningoencephalocele.

The patient returned two weeks later for a follow-up targeted assessment of the fetal brain anatomy. The previously identified sac was visualized again, with both the cerebellum and midbrain herniating through the posterior skull defect (Figure 2B). cfDNA testing was not performed, and diagnostic genetic testing via chorionic villus sampling (CVS) was offered 
but declined. She subsequently returned to her country of origin (China) for a termination of pregnancy, and genetic testing was not performed on the products of conception.

\section{Case 3}

A 40-year-old G2P1 patient without any medical co-morbidities who had a previous normal vaginal delivery without any antenatal complications was initially referred for a viability ultrasound and for cfDNA testing as a primary screening test for fetal chromosomal abnormalities. The initial ultrasound showed an embryo size consistent with 10 weeks and 4 days, and a cystic structure (measuring $3.8 \times 3.4$ x $4.4 \mathrm{~mm}$ ) protruding from the posterolateral region of the embryonic head (Figure 3A). The relatively normal brain shape and anatomy also excluded a diagnosis of acrania. The patient chose not to have cfDNA testing and the option of diagnostic testing via CVS or Amniocentesis was discussed with her.

On a repeat ultrasound examination at 13 weeks of gestational age, the same parieto-occipital lesion was visualized, but this time with a large defect and herniation of a large portion of brain tissue (Figure 3B). Given the relatively large size of the lesion with an overall secondary reduction of intracranial contents and of the skull size, this pregnancy was associated with an extremely poor prognosis. After discussion, the patient decided to continue the pregnancy and declined diagnostic testing. Four ultrasound scans were performed subsequently at 16, 20, 25 and 31 weeks of gestational age and all showed increasing size of the lesion with more involvement of brain tissue (Figure 3C).

This article is protected by copyright. All rights reserved. 
The patient delivered a male infant at 40 weeks with a birth weight of $3120 \mathrm{~g}$ and head circumference of $29 \mathrm{~cm}$. He had an Apgar score of 4, 2 and 1 at one, five and ten minutes, respectively. The neonate subsequently passed away three hours later as a result of respiratory complications.

This article is protected by copyright. All rights reserved. 


\section{Discussion}

In this cases series, we present three cases of very early diagnosis of fetal encephalocele that showed different evolution throughout pregnancy. In all three cases, the patients decided to have cfDNA testing as a primary screening test for fetal chromosomal abnormalities, and on ultrasound examination prior to cfDNA testing a skull defect was identified. All three cases initially presented as a small cystic lesion at 10 weeks, with the latter two cases evolving to include brain involvement by 13 weeks of gestational age. Given our small number of cases and the lack of clear differentiating factors between the three cases, it is difficult to predict the natural evolution of the condition. However, it appears that by 13 weeks of gestational age, ultrasound examination will likely serve as an indicator of whether or not the defect has differentiated into a meningocele (without encephalic tissue herniation) or a meningoencephalocele. One study had previously documented a solid-looking lesion at 21 weeks of gestation evolving into a cystic lesion with soft tissue strands at around 26 weeks of gestation. ${ }^{9}$ Combined with our observations, it is clear that the progression of said condition is highly variable. Subsequent imaging investigations via sonographic examination or magnetic resonance imaging will allow for monitoring, better evaluation and management of the condition as the pregnancy progresses, and for appropriate counselling of the parents regarding the postnatal prognosis.

In this era where the usage of cfDNA analysis for detection of chromosomal abnormalities has become relatively common, performing a pre-cfDNA test ultrasound examination will allow for a window of opportunity to assess early fetal anatomy and thereby highlight any early signs of major abnormalities. ${ }^{7}$ The pre-cfDNA test ultrasound examination will also 
provide other benefits such as ruling out miscarriage, vanishing twin and confirming gestational age, thereby potentially changing pregnancy management. ${ }^{6}$ In a retrospective cohort study conducted by Vora et al., 16.1\% of patients who had undergone cfDNA testing had an ultrasound finding that impacted pre-test counselling and subsequent screening approaches. ${ }^{6}$ Another retrospective cohort study conducted by Reiff et al. also found that in their cohort of high-risk women, abnormal ultrasound results were found in 3.5\% of patients with a screen-negative cfDNA test result. ${ }^{10}$ Combined with the findings of both studies, this case series further highlights the importance of routinely performing a pre-cfDNA test ultrasound. In cases of abnormal findings, the rate of pathogenic chromosome abnormalities missed by cfDNA screening is as high as $8 \%$, and thus cfDNA testing should be not be offered to these patients as a screen-negative result would be falsely reassuring. ${ }^{11}$ Diagnostic testing with fetal chromosomal microarray should be considered instead.

In our three cases, one patient had fetal chromosomal microarray testing of chorionic villi, while the others declined diagnostic testing following genetic counselling. NTDs, including encephaloceles, are known to have associations with chromosomal abnormalities including, but not limited to, aneuploidy. Previous studies have shown that between $7-17 \%$ of encephaloceles are associated with chromosomal abnormalities, ${ }^{12}$ of which the most common aneuploidy is trisomy $21 .{ }^{12-14}$ It is therefore important to offer these patients diagnostic genetic testing as there may be value in prognostication, determining the probability of recurrence in future pregnancies, and thus aid in pregnancy counselling. Apart from aneuploidy, encephaloceles are associated with other genetic disorders such as MeckelGruber syndrome. Meckel-Gruber syndrome is a rare and lethal autosomal recessive 
condition characterized by cystic renal dysplasia, occipital encephalocele or other central nervous system anomalies, and polydactyly. ${ }^{15}$ All three of our cases had isolated occipital lesions, which suggested against Meckel-Gruber syndrome.

In terms of management, neurosurgical opinion is warranted. In a previous study published by Kiymaz et al., factors such as size of the lesion, amount of neural tissue contained, ventriculomegaly, and other accompanying abnormalities negatively impacted the prognosis of these patients. ${ }^{3}$ The amount of neural tissue involved is associated with the severity of subsequent neurodevelopmental delay. It was previously reported that approximately only $17 \%$ of patients with encephaloceles had normal development, in contrast to $83 \%$ of patients reported having severe neurodevelopmental and physical delay. ${ }^{16}$ Despite the mainstay of treatment being surgical correction, encephalocele remains a condition with very high morbidity and mortality rates despite appropriate treatment operatively and post-operatively. ${ }^{3}$ In conclusion, the identification of major fetal defects at earlier gestational ages will inevitably rise with the increasing use of cfDNA and pre-test ultrasound examination. Although encephaloceles are associated with poor prognosis and antenatal evolution is rather unpredictable, early identification may lead to changes in screening and diagnostic testing pathways.

This article is protected by copyright. All rights reserved. 


\section{References}

1. Siffel C, Wong LY, Olney RS, Correa A. Survival of infants diagnosed with encephalocele in Atlanta, 1979-98. Paediatr Perinat Epidemiol. 2003;17(1):40-8.

2. Liao S, Tsai, PY., Chen, YC., Chang, CH., Ko, HC., Chang, FM. Prenatal Diagnosis of Fetal Encephalocele Using Three-dimensional Ultrasound. Journal of Medical Ultrasound. 2012;20(3):150-4.

3. Kiymaz N, Yilmaz N, Demir I, Keskin S. Prognostic factors in patients with occipital encephalocele. Pediatr Neurosurg. 2010;46(1):6-11.

4. Lo BW, Kulkarni AV, Rutka JT, Jea A, Drake JM, Lamberti-Pasculli M, et al. Clinical predictors of developmental outcome in patients with cephaloceles. J Neurosurg Pediatr. 2008;2(4):254-7.

5. Fong KW, Toi A, Salem S, Hornberger LK, Chitayat D, Keating SJ, et al. Detection of fetal structural abnormalities with US during early pregnancy. Radiographics. 2004;24(1):157-74.

6. Vora NL, Robinson S, Hardisty EE, Stamilio DM. Utility of ultrasound examination at 10-14 weeks prior to cell-free DNA screening for fetal aneuploidy. Ultrasound Obstet Gynecol. 2017;49(4):465-9.

7. Rolnik DL, Wertaschnigg D, Benoit B, Meagher S. Sonographic detection of fetal abnormalities before 11 weeks of gestation. Ultrasound Obstet Gynecol. 2019.

8. Meagher S, Hui L. Alobar holoprosencephaly detected in a 9-week embryo. Am J Obstet Gynecol. 2019;221(1):73-4.

This article is protected by copyright. All rights reserved. 
9. Budorick NE, Pretorius DH, McGahan JP, Grafe MR, James HE, Slivka J. Cephalocele detection in utero: sonographic and clinical features. Ultrasound Obstet Gynecol. 1995;5(2):77-85.

10. Reiff ES, Little SE, Dobson L, Wilkins-Haug L, Bromley B. What is the role of the 11- to 14-week ultrasound in women with negative cell-free DNA screening for aneuploidy? Prenat Diagn. 2016;36(3):260-5.

11. Benachi A, Letourneau A, Kleinfinger P, Senat MV, Gautier E, Favre R, et al. Cellfree DNA analysis in maternal plasma in cases of fetal abnormalities detected on ultrasound examination. Obstet Gynecol. 2015;125(6):1330-7.

12. Sepulveda W, Corral E, Ayala C, Be C, Gutierrez J, Vasquez P. Chromosomal abnormalities in fetuses with open neural tube defects: prenatal identification with ultrasound. Ultrasound Obstet Gynecol. 2004;23(4):352-6.

13. Goldstein RB, LaPidus AS, Filly RA. Fetal cephaloceles: diagnosis with US. Radiology. 1991;180(3):803-8.

14. Kennedy D, Chitayat D, Winsor EJ, Silver M, Toi A. Prenatally diagnosed neural tube defects: ultrasound, chromosome, and autopsy or postnatal findings in 212 cases. Am J Med Genet. 1998;77(4):317-21.

15. Parelkar SV, Kapadnis SP, Sanghvi BV, Joshi PB, Mundada D, Oak SN. MeckelGruber syndrome: A rare and lethal anomaly with review of literature. J Pediatr Neurosci. 2013;8(2):154-7.

16. French BN. Midline fusion defects and defects of formation. Youmans JR (ed): Neurological Surgery. Philadelphia: Saunders; 1990. p. 1164-9. 


\section{FIGURE LEGENDS}

Figure 1. Antenatal imaging and postnatal aspect of the encephalocele in case 1. A) Sagittal image at 10 weeks and 6 days of gestational age (based on crown rump length) showing an occipital lesion; B) Axial image at 13 weeks and 2 days of gestational age, showing the previously identified occipital lesion increasing in size; C) Sagittal slice of a magnetic resonance image at 24 weeks of gestational age demonstrating the occipital encephalocele (yellow arrow); D) Picture showing the physical appearance of the lesion after birth.

Figure 2. Ultrasound images at different gestational ages in case 2. A) Sagittal image at 10 weeks and 6 days of gestational age showing the occipital cystic lesion; B) The lesion has evolved and started to include both the cerebellum and the midbrain at 12 weeks and 5 days of gestational age.

Figure 3. Sonographic appearances of the encephalocele in case 3. A) Sagittal image at 10 weeks and 4 days of gestational age (based on crump rump length) showing the cystic structure protruding from the posterolateral region of the fetal head; B) Sagittal image at 12 weeks and 6 days of gestational age; C) Sagittal image at 25 weeks of gestational age demonstrating a large occipital skull defect with herniation of a significant amount of brain tissue (yellow arrows).

This article is protected by copyright. All rights reserved. 


\section{Please wait...}

If this message is not eventually replaced by the proper contents of the document, your PDF viewer may not be able to display this type of document.

You can upgrade to the latest version of Adobe Reader for Windows®, Mac, or Linux® by visiting http://www.adobe.com/go/reader_download.

For more assistance with Adobe Reader visit http://www.adobe.com/go/acrreader.

Windows is either a registered trademark or a trademark of Microsoft Corporation in the United States and/or other countries. Mac is a trademark
of Apple Inc., registered in the United States and other countries. Linux is the registered trademark of Linus Torvalds in the U.S. and other countries. 


\section{Please wait...}

If this message is not eventually replaced by the proper contents of the document, your PDF viewer may not be able to display this type of document.

You can upgrade to the latest version of Adobe Reader for Windows®, Mac, or Linux® by visiting http://www.adobe.com/go/reader_download.

For more assistance with Adobe Reader visit http://www.adobe.com/go/acrreader.

Windows is either a registered trademark or a trademark of Microsoft Corporation in the United States and/or other countries. Mac is a trademark
of Apple Inc., registered in the United States and other countries. Linux is the registered trademark of Linus Torvalds in the U.S. and other countries. 


\section{Please wait...}

If this message is not eventually replaced by the proper contents of the document, your PDF viewer may not be able to display this type of document.

You can upgrade to the latest version of Adobe Reader for Windows®, Mac, or Linux® by visiting http://www.adobe.com/go/reader_download.

For more assistance with Adobe Reader visit http://www.adobe.com/go/acrreader.

Windows is either a registered trademark or a trademark of Microsoft Corporation in the United States and/or other countries. Mac is a trademark
of Apple Inc., registered in the United States and other countries. Linux is the registered trademark of Linus Torvalds in the U.S. and other countries. 


\section{Please wait...}

If this message is not eventually replaced by the proper contents of the document, your PDF viewer may not be able to display this type of document.

You can upgrade to the latest version of Adobe Reader for Windows®, Mac, or Linux® by visiting http://www.adobe.com/go/reader_download.

For more assistance with Adobe Reader visit http://www.adobe.com/go/acrreader.

Windows is either a registered trademark or a trademark of Microsoft Corporation in the United States and/or other countries. Mac is a trademark
of Apple Inc., registered in the United States and other countries. Linux is the registered trademark of Linus Torvalds in the U.S. and other countries. 


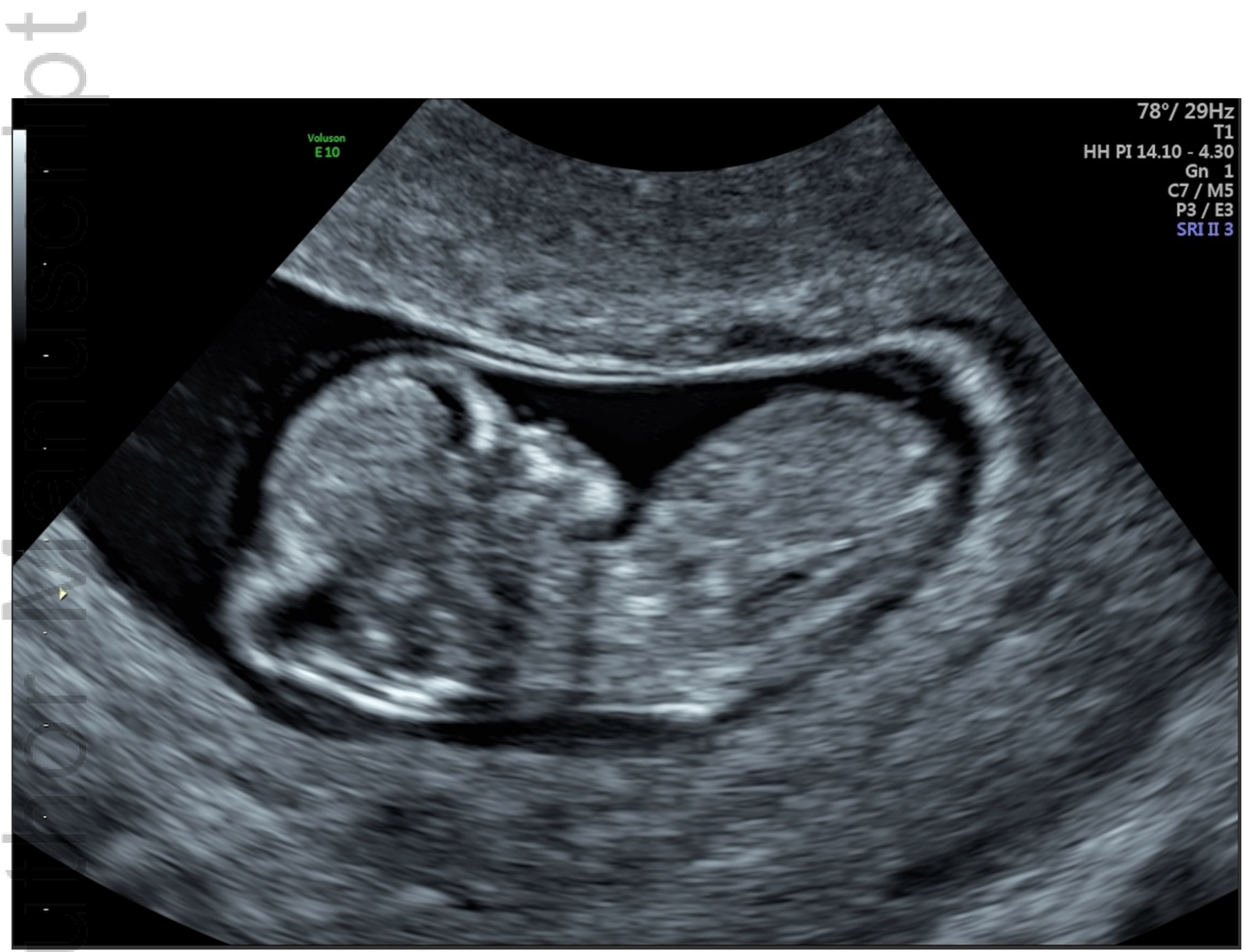

JUM_15217_Figure 1A 300dpi.png

This article is protected by copyright. All rights reserved. 


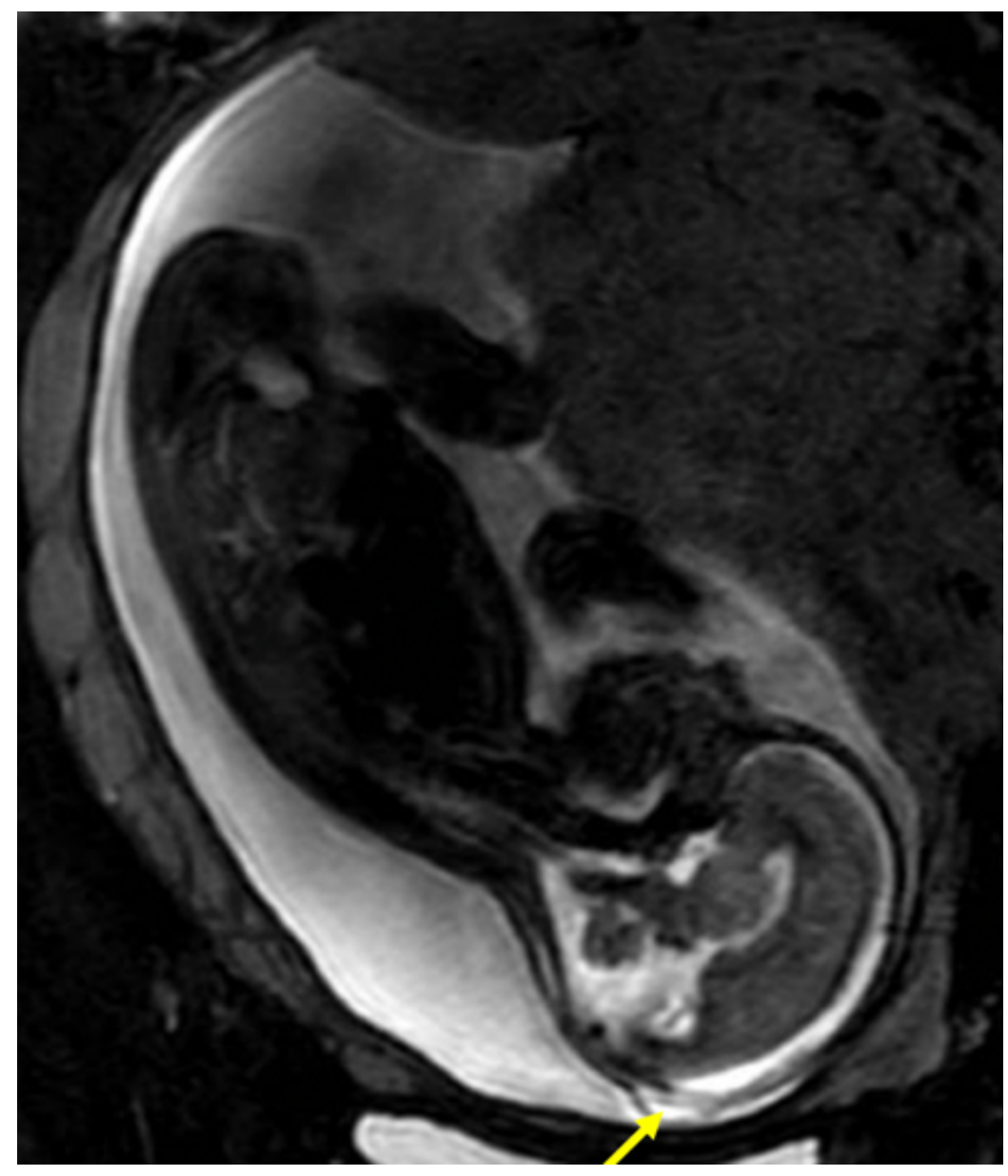

JUM_15217_Figure 1C 300dpi.png

This article is protected by copyright. All rights reserved. 

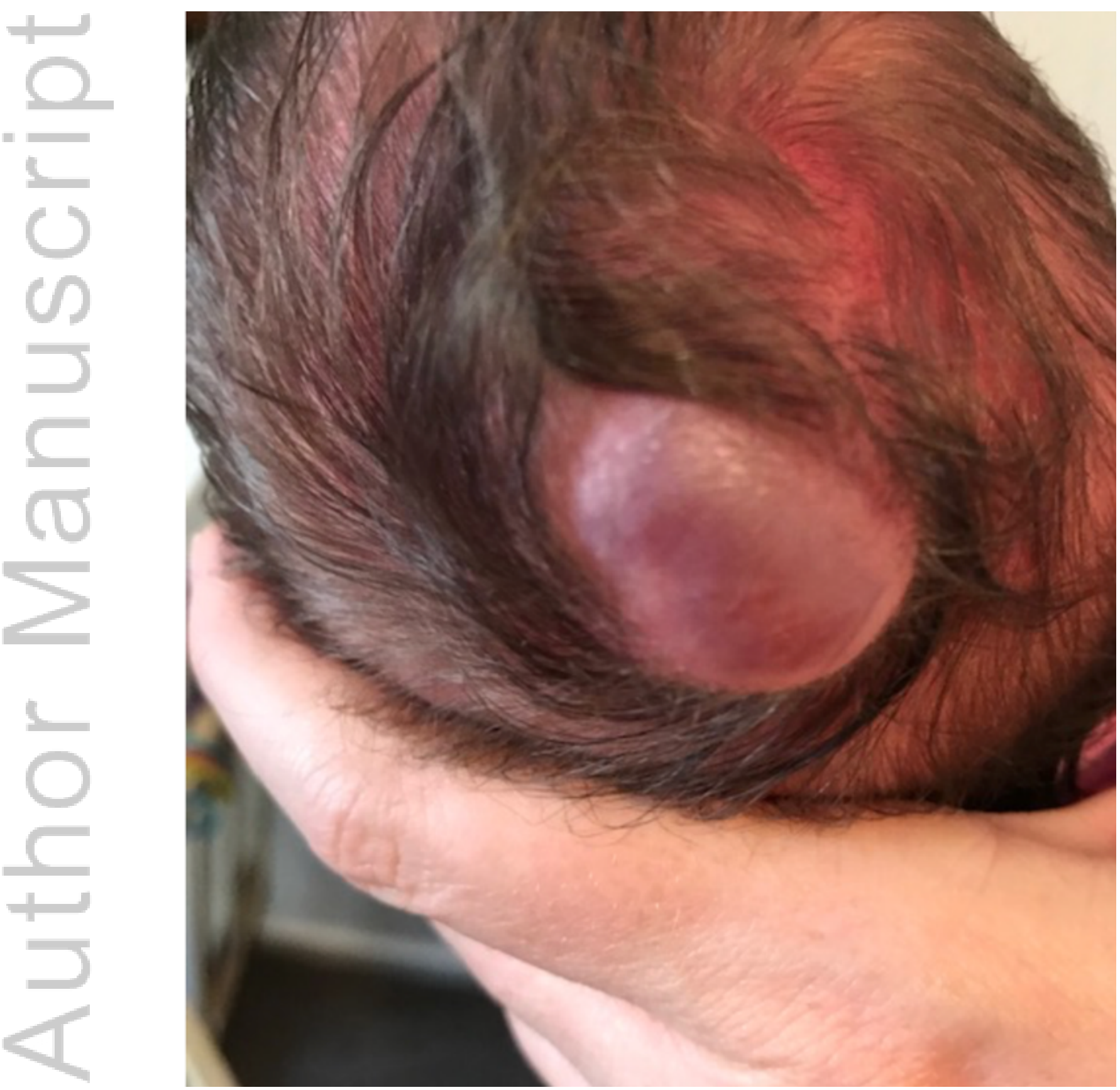

JUM_15217_Figure 1D 300dpi.png

This article is protected by copyright. All rights reserved. 


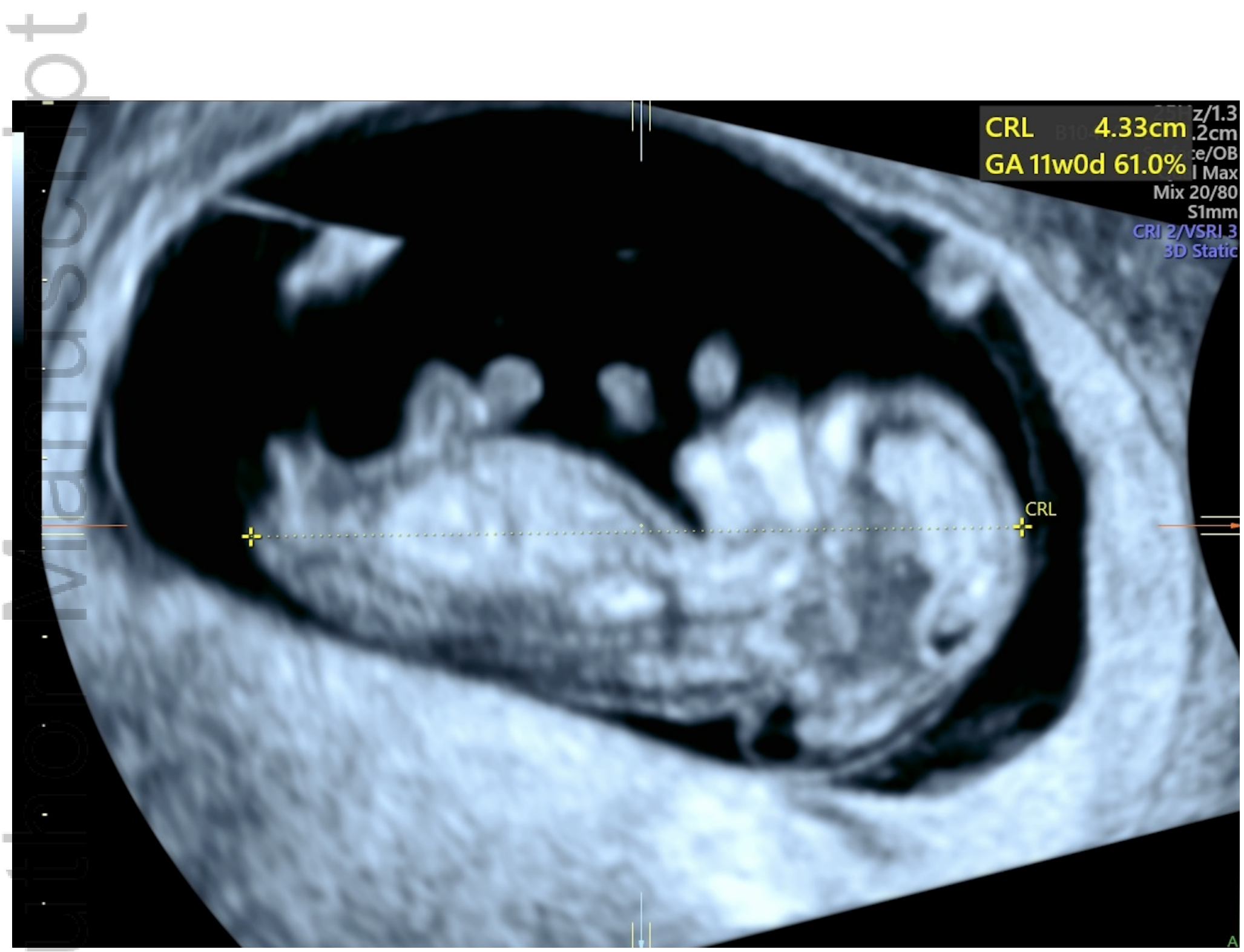

JUM_15217_Figure 2A 300dpi.png 


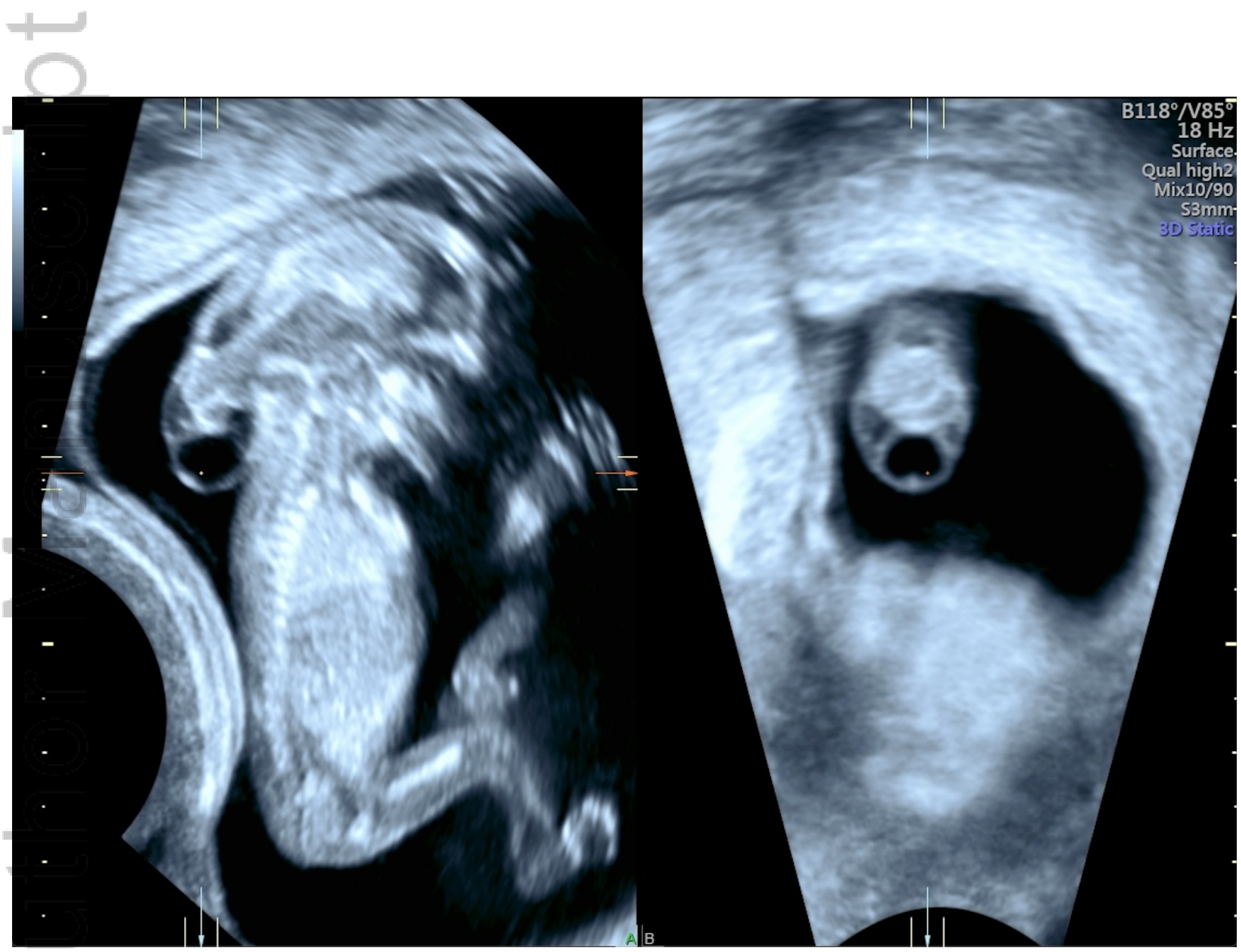

JUM_15217_Figure 2B 300dpi.png 


\section{WEEKS}

LATER

JUM_15217_Figure 3B 300dpi.png 


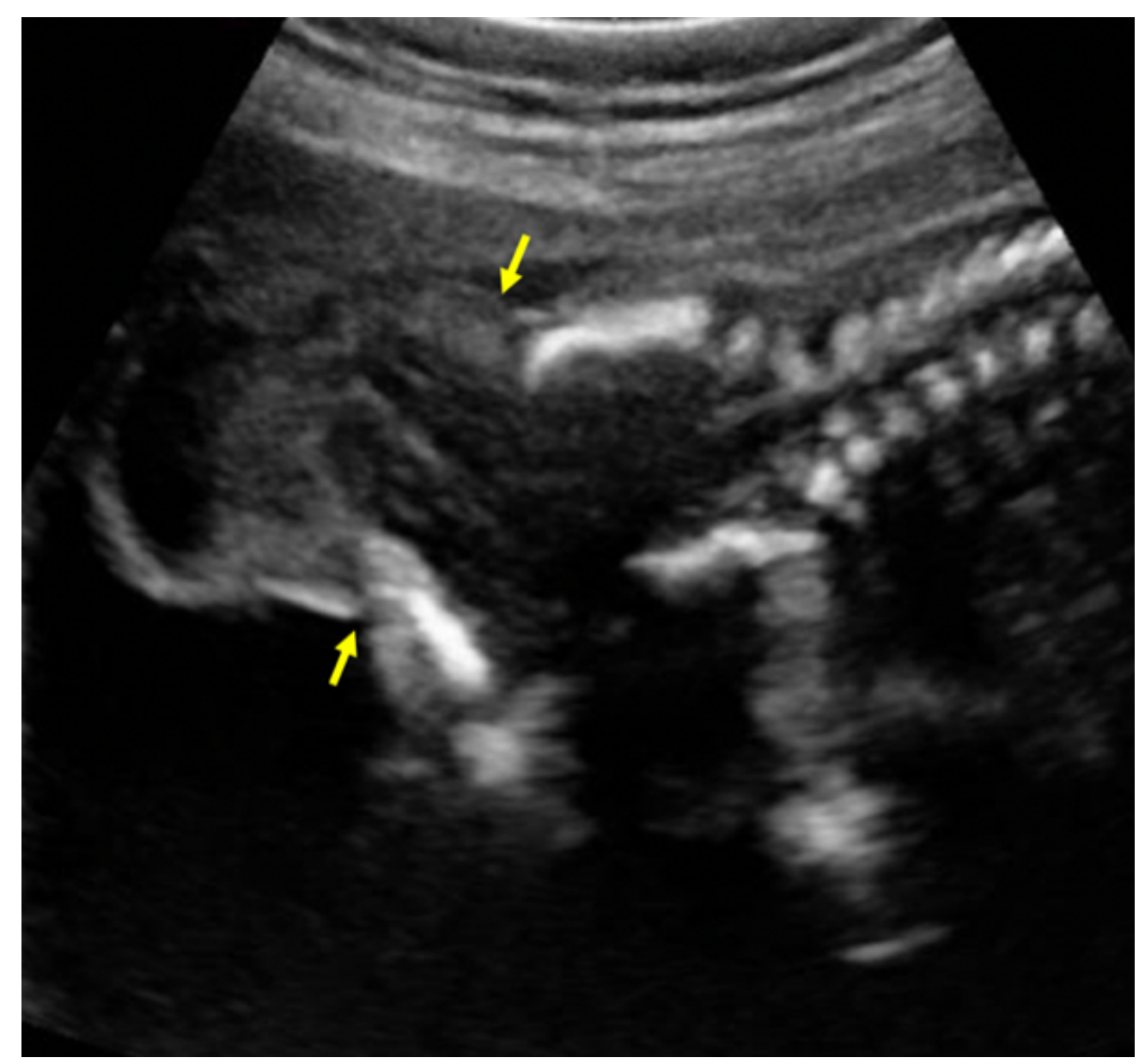

JUM_15217_Figure 3C 300dpi.png

This article is protected by copyright. All rights reserved. 